\title{
SURGICAL MANAGEMENT OF OBLIQUE DIPHYSEAL TIBIAL FRACTURE IN CANINE
}

\author{
D. GHOSH*, V. Kumar, A. DEBNATH, V. LALZAWMLiAnA \\ P. MUKHERJEE ${ }^{1}$, S. CHOWDHURY ${ }^{1}$ AND S. K. NANDI \\ Department of Surgery and Radiology \\ Faculty of Veterinary and Animal Sciences \\ West Bengal University of Animal and Fishery Sciences \\ Kolkata- 700 037, India
}

\begin{abstract}
A cross breed medium size dog, aged nine months was presented in the clinic with a history of accident, swelling on the lateral aspect of tibia. The radiological examination confirmed a complete oblique mid shaft fracture of tibia. Hybrid internal fixation with intra medullary pinning combined with cerclage wiring was used for fracture repair with standard surgical approach to bone under standard anaesthetic protocol. The patient was successfully treated and recovered completely after 2 months.
\end{abstract}

Key words: Anaesthetics, Cerclage wiring, Fracture, Intramedullary pin

Fractures are one of the most common clinical presentations observed in dogs. They are most commonly caused by accidental trauma. Tibial fractures occur very frequently, and they account for around $20 \%$ of all long bone fractures (Unger et al., 1990; Seaman and Simpson, 2004). Tibial shaft fracture is most common accounting for nearly $73 \%$ of tibial fractures
(Zaal and Hazewinkel, 1996). Tibia is covered by less musculature and soft tissues, and being an important weight bearing bone, it is very prone for fracture (Harasen, 2003). Tibial fractures are predisposed to open fractures due to the smaller amount of soft tissue surrounding the tibial bone (Pope, 1998).

\footnotetext{
* Corresponding Author

${ }^{1}$ Department of Veterinary Clinical Complex, West Bengal University of Animal and Fishery Sciences, Kolkata- 700037
} 
A medium sized male cross breed dog, weighing $14 \mathrm{~kg}$, aged 9 months was presented in clinic with a history of accident. The physical examination of the patient revealed non-weight bearing lameness of left hind limb, swelling over the lateral aspect of tibia with crepitation on palpation. Radiological examination confirmed complete, diphyseal oblique fracture of left tibia (Fig. 1).

The dog was planned for internal immobilization with hybrid fixation technique in combination with intramedullary pinning and cerclage wiring. The animal was administered with ceftrioxone @10 mg/Kg b.wt. b.i.d, i/m, temporary immobilization with Robert Jhones bandage for 3 days before surgical intervention. The animal was prepared for aseptic surgery by routine way in the medial aspect of the fractured tibia and fibula. The dog was administered with atropine sulphate @ $0.02 \mathrm{mg} / \mathrm{Kg}$ s/c, xylazine $1 \mathrm{mg} / \mathrm{Kg}$ and butorphanol $0.2 \mathrm{mg} / \mathrm{Kg} \quad \mathrm{i} / \mathrm{m}$, as preanasethetics. General anaesthesia was maintained with diazepam $1 \mathrm{mg} / \mathrm{Kg}$ and propofol $2 \mathrm{mg} / \mathrm{Kg}$ intravenously. The incision was made at the cranio-medial aspect of tibial bone of effected limb and the fractured parts were exposed. Drilling was done obliquely on the medial side of the proximal tibia until it reached the medullary space. Normograde insertion of intramedullary pin of $3.5 \mathrm{~mm}$ depending age of the dog and diameter of the tibia was performed from the medial side of the proximal tibia (Howard, 1991). The pin was chosen in such a way that it fills approximately two third of the medullary cavity. A cerclage wiring of the edges of the fractured bones was done with 20 gauge stainless steel orthopadeic wire to support the immobilization and maintain the bone in its alignment. The intramedullary pin was so used that the distal tip of the pin anchored in the distal epiphysis of the tibia firmly and the proximal part is cut bending the proximal edge medially. The surgical wound was closed in a routine manner with non-absorbable synthetic suture material. Post-operatively, the operated limb was given external support with modified Robert Jones's bandage with antiseptic dressing of the wound on $3^{\text {rd }}, 5^{\text {th }}$ and $7^{\text {th }}$ day. The animal was administered with ceftrioxone (@10mg/Kg b.wt) and meloxicam (@ $0.4 \mathrm{mg} / \mathrm{Kg} \mathrm{b.wt)}$ for 7 and 3 days respectively. Calcium and vitamin $\mathrm{D}$ supplement was also given for 1 month. The client was advised to restrict the activity of the animal for first 2 weeks and later the dog was allowed leash walk. The radiograph taken immediately after surgery and subsequently at a regular fortnight intervals were evaluated for fracture healing, pin position, any complication, time taken for callus formation and time taken for complete bone healing (Fig. 2 and Fig. 3). The sutures and intramedullary pin were removed after 14 and 42 days of surgery respectively and the bone eventually healed after 2 months. 
Indian Journal of Animal Health, June, 2018

Surgical management of tibial fracture in canine
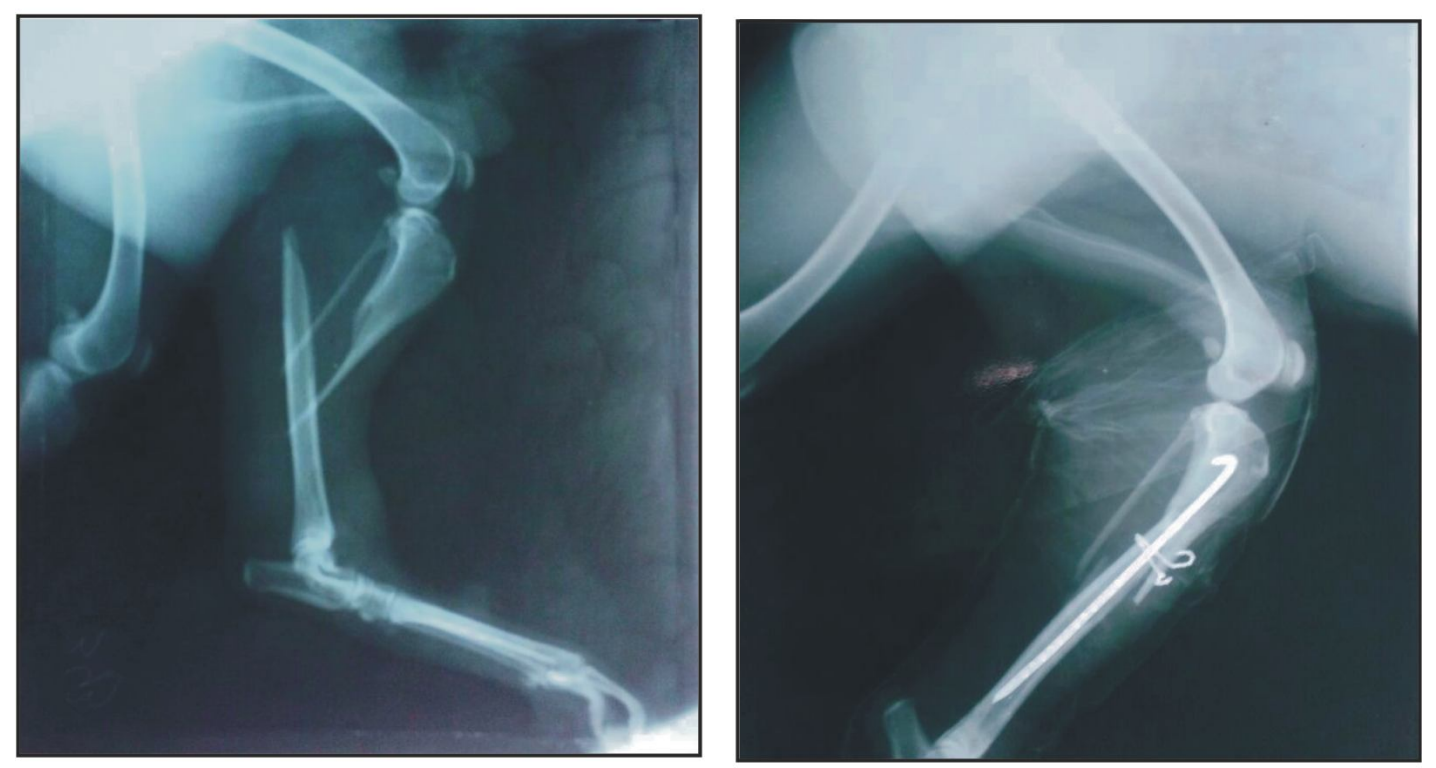

Fig. 1. Radiographic diagnosis of fracture Fig. 2. Radiograph after the operation
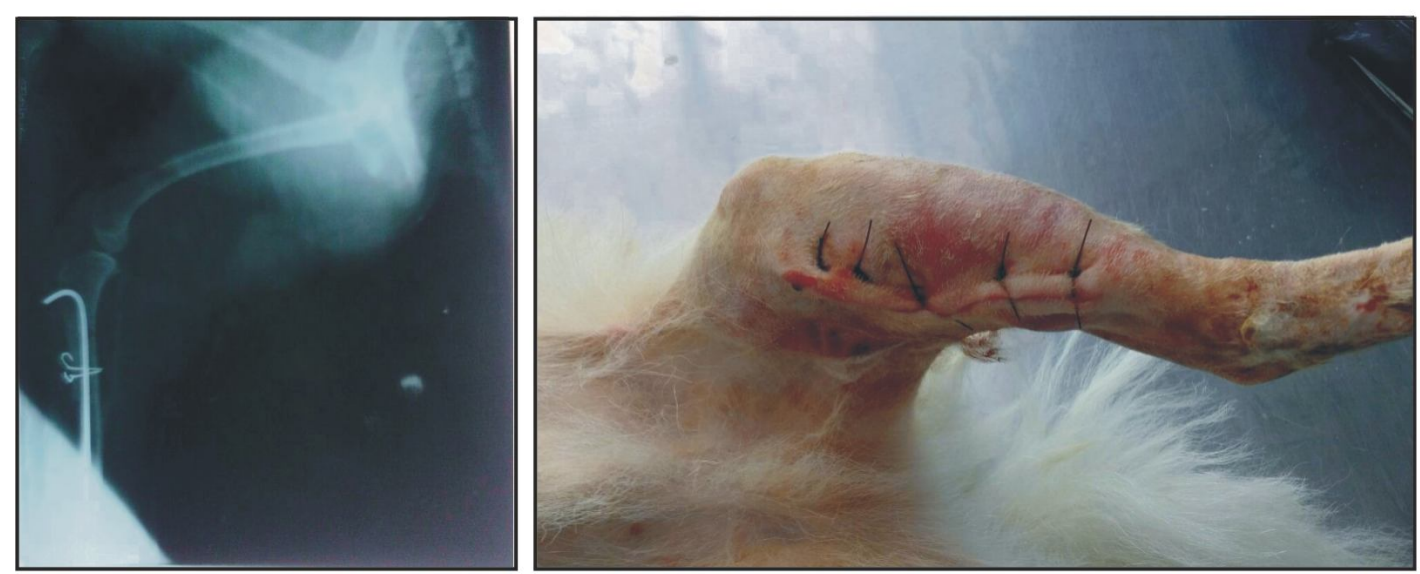

Fig. 3. Radiograph taken after 2 weeks Fig. $4.10^{\text {th }}$ days post operative wound 
Intramedullary pinning of the tibial fracture and the ancillary fixation that is necessary depend on the fracture configuration. In this present study intramedullary pin was chosen such that it fills approximately two third of the medullary canal (Boudrieau, 1991). Intramedullary pin was placed in such a way that it should not interfere with the normal joint function. Retrograde pin insertion from the fracture site must be avoided because if the pin exits within the stifle joint can cause severe joint damage (Pardo, 1994). Normograde insertion of an intramedullary pin was performed from the medial side of the proximal tibia to prevent complications with the joints (Howard, 1991). The radiograph taken immediately after the operation revealed good positioning and alignment of fracture ends. Subsequent radiographs revealed initiation of callus formation on $15^{\text {th }}$ days, resorption of primary callus on $30^{\text {th }}$ day and complete remodeling with evidence of diphyseal medullary cavity on $45^{\text {th }}$ day at the fracture site.

Since the animal presented was of growing age, fixation provided by intramedullary pinning was opted to prevent premature closure of the growth plate (Lipowitz et al., 1993), which can be a problem in other method of fixation. In growing dogs if

\section{REFERENCES}

Boudrieau RJ, 1991. Principles of long bone fracture repair. Semin Vet Med Surg Small Anim, 7: 44 plates or screws are used as fixation devices then the implants must be removed as early as possible in order not to affect the growth plate. In case of intramedullary pinning, the pin can be left in place unless loss of function and pin loosening is present (Piermattei and Flo, 1997). The intramedullary pinning of long bone cannot neutralize the rotation force of bone as a result there may be delayed and mal union. A full cerclage wiring was done to hold both fracture ends opposed to each other and to restrict the rotational instability of fractured tibia. In some cases cerclage wires were thought to be the reason for failure to heal in some fractures (Withrow, 1978), and the mechanism was thought to damage the blood supply. But extensive investigation of the blood supply to the callus has shown that it is not affected by stable cerclage (Wilson, 1991). Since the cerclage wiring was stable enough such complications and delayed healing was not observed here. But we have removed the pin after clinical union in order to prevent further complication. The wiring was kept in situ without perceptible complication for a period of 2 years of follow up time. Clinical union occurs after 8 weeks and the patient regained original locomotory function.

Harasen G, 2003. Common long bone fracture in small animal practice. Part 2. Can Vet J, 44: 503-504 
Howard PE, 1991. Principles of intramedullary pin and wire fixation. Semin Vet Med Surg Small Anim, 6: 52

Lipowitz AJ, Caywood DD, Newton CD and Finch ME, 1993. Small Animal Orthopedics, Illustrated Surgical Approaches and Procedures, Mosby, St Louis, pp 270-273

Pardo AD, 1994. Relationship of tibial intramedullary pins to canine stifle joint structure: A comparison of normograde and retrograde insertion. J Am Anim Hoso Assoc, 30: 369

Piermattei DL and Flo GL, 1997. Brinker, Piermattei and Flo's Handbook of Small Animal Orthopedics and Fracture Repair, WB Saunders Company, Philadelphia, pp 586-594

Pope ER, 1998. Fixation of Tibial Fracture. In: Current technique in small animal surgery. Bojrab M.J. Ed., Williams \&
Wilkins, Baltimore, pp 1050-1055

Seaman JA and Simpson AM, 2004. Tibial fractures. Clin Tech Small Anim Pract, 19: $151-167$

Unger MP, Montavon M and Heim UF, 1990. Classification of fractures of the long bones in the dog and cat: introduction and clinical application. Vet Comp Orthop Traumatol, 3: 41-50

Wilson JW, 1991. Vascular supply to normal bone and healing fractures. Semin Vet Med Surg Small Anim, 6: 26

Withrow SJ, 1978. Use and misuse of full cerclage wires in fracture repair. Vet Clin North Am, 8: 201

Zaal MD and Hazewinkel HA, 1996. Classifications of 202 tibial fractures in dogs and cats. Tijdschr Diergeneeskd, 121: $218-223$

Article received on 15.01.2018 and accepted for publication on 20.05.2018 